\title{
Frecuencia de los genes de fusión TEL/AML1 y BCR/ABL en pacientes pediátricos con leucemia linfoblástica aguda
}

\author{
Carmen Gloria Artigas $A^{\text {la }}$, María Elena Cabrera $C^{2}$, \\ Angélica Melo $A^{3 a}$, Eduardo Páez $F^{4}$, Mónica Arriagada $M^{4}$, \\ Carmen Astete $A^{5}$, Iván Roa $E^{1,3}$, Juan Carlos Roa $S^{3}$. \\ Frequency of TEL/AMLI and BCR/ABL \\ fusion genes in children \\ with acute lymphoblastic leukemia
}

Background: $t(12 ; 21) \quad(p 12 ; q 22)$ and $t(9 ; 22) \quad(q 34 ; q 11)$ translocations have prognostic significance in acute lymphoblastic leukemia (AL). The fusion genes TEL/AML1 y BCR/ABL, generated by these translocations, can be easily detected using molecular biology technique. Aim: To study the frequency of TEL/AML1 y BCR/ABL fusion genes in children with ALL Material and methods: Fifity six children with ALL (age range 1 month- 14 years) were studied, thirty eight from our Temuco Hospital and 18 from the Metropolitan Region. TEL/AML1 y BCR/ABL fusion genes were detected in bone marrow samples using a reverse transcriptase nested polymerase chain reaction (RT-PCR). Results: TEL/AML 1 and BCR/ABL fusion gene transcripts were detected in $13(23 \%)$ and $2(4 \%)$ children, respectively. No differences in survival were observed between children with positive or negative transcripts for TEL/AML1 fusion gene. However, those positive for BCR/ABL fusion gene, had a significantly lower survival. Conclusions: The frequency of TEL/AML1 and BCR/ABL fusion gene transcripts in these children with AL is similar to that described by other authors (Rev Méd Chile 2006; 134: 1367-76).

(Key words: Fusion proteins, BCR-ABL; Leukemia, lymphocytic, acute; TEL-AML1 fusion protein)

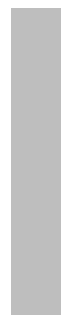

Recibido el 17 de octubre, 2005. Aceptado el 21 de abril, 2006.

Trabajo financiado por la Universidad de La Frontera, a través del Proyecto DIUFRO \#2121.

${ }^{1}$ Banco de Tumores Temuco, Departamento Anatomía Patológica, Clínica Alemana de Temuco. ${ }^{2}$ Departamento de Medicina Interna, Sección Hematología, Hospital del Salvador, Universidad de Chile, Santiago. ${ }^{3}$ Departamentos de Anatomía Patológica y ${ }^{4}$ Cirugía Infantil y Pediatría, Facultad de Medicina, Universidad de La Frontera, Temuco. ${ }^{5}$ Laboratorio de Citogenética, Hospital Luis Calvo Mackenna, Santiago, Chile.

aTecnólogo Médico Licenciado.

Correspondencia a: TM Carmen Gloria Artigas Allaire. Banco de Tumores Temuco, Dpto. Anatomía Patológica, Clínica Alemana de Temuco. Senador Estebanez 645. Temuco-Chile. Fono/Fax: 45-296591. E mail: btt@ufro.cl 
L a aplicación de las técnicas de biología molecular en el estudio de las neoplasias hematológicas ha significado un gran avance, permitiendo conocer mejor la patogénesis de estas enfermedades, por su alta sensibilidad y especificidad son de gran utilidad para el diagnóstico, pronóstico, seguimiento y, por tanto, de ayuda en las decisiones clínicas. En la leucemia linfoblástica aguda (LA) entre $60 \%$ y $75 \%$ de los pacientes presentan anormalidades genéticas numéricas, como la hiper o hipodiploidía, o estructurales como translocaciones cromosómicas, que llevan a la formación de genes de fusión o desregulación de la expresión génica e inactivación de genes supresores de tumores. Estas alteraciones recurrentes, se han asociado a caractenísticas clínicas y pronósticas específicas. Las translocaciones cromosómicas más frecuentes en la LA infantil son: $\mathrm{t}(12 ; 21)(\mathrm{p} 12 ; \mathrm{q} 22), \mathrm{t}(1 ; 19)$ (q23;p13), t(4;11)(q21;q23) y $\mathrm{t}(9 ; 22)(\mathrm{q} 34 ; \mathrm{q} 11)^{1-5}$. Los genes de fusión comprometidos en estas alteraciones pueden ser detectados mediante reacción de polimerasa en cadena, previa transcripción reversa (RT-PCR), tanto para el diagnóstico como para el estudio de la enfermedad residual durante el tratamiento, ya que la sensibilidad de esta técnica permite identificar una célula leucémica entre $10^{-4}$ a $10^{-6}$ células normales, dependiendo si se utiliza un PCR simple 0 en nido ${ }^{6}$.

La $\mathrm{t}(12 ; 21)(\mathrm{p} 12 ; \mathrm{q} 22)$ resulta de la translocación entre el gen TEL (ETV6) del cromosoma $12 \mathrm{y}$ el gen AML1 (CBFA2 core-binding factor) del cromosoma 21, originando el transcripto de fusión TEL/ AML1 ${ }^{2,3,7}$. Esta anormalidad genética, que comúnmente aparece en útero, probablemente es el evento inicial en la génesis de la LAA de estirpe $B$ en niños ${ }^{8-10}$. El gen de fusión TEL/AML1 se ha detectado con una frecuencia de $18 \%$ a $33 \%$, en diferentes poblaciones como Brasil ${ }^{11}$, Estados Unidos $^{12}$, Europa 13,14 , República Checa ${ }^{15}$, Turquía $^{16}$, Australia ${ }^{17}$ y Japón ${ }^{18}$. Este gen de fusión identifica a un subgrupo de niños con LUA con características definidas al diagnóstico tales como: edad entre 2 y 10 años, bajo recuento de leucocitos, inmunofenotipo de estirpe $\mathrm{B}$ e índice de ADN no hiperdiploide. Dentro de este grupo etáreo, la mayor frecuencia de pacientes TEL/AML1(+) se ubica en el rango de 2 a 5 años ${ }^{13,14,19}$. La LA TEL/AML1(+) está biológicamente caracterizada por una prolongada remisión completa y una excelente sobrevida libre de evento (SLE) a largo plazo. La mayoría de las publicaciones asocian esta alteración con un pronóstico favorable ${ }^{2,20,21}$. Sin embargo, varios estudios han demostrado que éste no parece ser un factor independiente de buen pronóstico y, por lo tanto, la buena respuesta de estos pacientes puede estar relacionada con otros factores como edad, sexo, recuento de leucocitos, inmunofenotipo, hiperploidia y respuesta a la terapia ${ }^{19,22-25}$. Por otra parte, existe evidencia que la presencia de anormalidades cromosómicas secundarias, tales como deleción del alelo TEL no translocado o duplicación del cromosoma 21, influirían adversamente en el curso clínico de los pacientes TEL/AML1 $(+)^{21,25}$.

La $t(9 ; 22)(q 34 ; q 11)$, conocida como cromosoma Philadelphia, fue la primera anormalidad citogenética identificada en leucemia ${ }^{26}$. Se produce cuando una parte del gen ABL localizado en el cromosoma 9 es transferida e insertada dentro del gen BCR del cromosoma 22, originando el transcripto de fusión BCR/ABL En la LA generalmente el punto de ruptura de los genes origina el reordenamiento e1a2, que lleva a la producción de la proteína de fusión p190 $\mathrm{BCR}-\mathrm{ABL}$, presentando una frecuencia de $2 \%-5 \%$ en la LA del niño. Además, en la $\amalg A$, aunque con menor frecuencia, puede presentarse el mismo reordenamiento descrito en la leucemia mieloide crónica, que genera la proteína de fusión p210 BCR-ABL1-4,6,10. La presencia del gen de fusión BCR/ABL en la LA está asociado a un pronóstico adverso, es un factor de riesgo independiente y los pacientes presentan una remisión de corta duración ${ }^{27,28}$.

La importancia de la detección de genes de fusión en la LA ha sido ampliamente comunicada en la literatura 2,5,6,8,9,11-25,27-28. En Chile existen escasas publicaciones en esta área utilizando la técnica RT-PCR ${ }^{29-32}$. Nuestro laboratorio ha comunicado previamente el montaje y aplicación de la detección del gen de fusión BCR/ABL en pacientes con leucemia, mediante RT-PCR ${ }^{30,32}$.

En el contexto del desarmollo de la biología molecular a nivel nacional y regional, y debido a la frecuencia del gen de fusión TEL/AML1 en pacientes con LA e importancia para el seguimiento de la enfermedad, nos propusimos montar la técnica para la detección de transcriptos de fusión del gen TEL/AML1 mediante RT-PCR, y aplicarla conjuntamente con la técnica para detección del gen de fusión BCR/ABL en un grupo de pacientes pediátri- 
cos con LA de la IX región y de la región Metropolitana.

\section{MATERIAL Y MÉTODO}

Casos. Se estudiaron, sin criterio de selección, 56 pacientes menores de 15 años con LLA de estirpe $\mathrm{B}$ al diagnóstico, 38 procedían de la Unidad de Hemato-Oncología del Hospital Temuco y 18 de hospitales de la región Metropolitana. El estudio se realizó entre los años 2000 y 2003. Las muestras de Temuco fueron obtenidas previo consentimiento informado de los padres. El presente estudio fue aprobado de acuerdo a la Declaración de Helsinki, por el Comité Ético-Científico del Servicio de Salud Araucanía Sur.

Estudio de inmunofenotipo. Se realizó en el Laboratorio de Inmunología del Hospital Regional de Temuco y en el Laboratorio de Referencia de Inmunofenotipo del Hospital del Salvador de Santiago. Los antígenos leucocitarios de superficie fueron detectados mediante inmunofluorescencia indirecta con los anticuerpos monoclonales HLA-DR, CD10, CD19, CD3, CD13, CD33 y CD34. La inmunoglobulina citoplasmática (Igc) y de superficie (Igs) fueron estudiadas con gammaglobulina de cabra anti-humana marcada con fluoresceína. La deoxinucleotidil transferasa terminal (TdT) se detectó mediante in- munofluorescencia indirecta. De acuerdo a la expresión de los antígenos de superficie, las LA se clasificaron en proB (HLA-DR+, CD19+, CD10-, Igc-), común (HLA-DR+, CD19+, CD10+, Igc-) y preB (HLA-DR+, CD19+, CD10+, Igc+) 33 .

Estudio citogenético. Se realizó en el Laboratorio de Referencia de Citogenética del Hospital Luis Calvo Mackenna de Santiago, mediante técnica de bandeo $\mathrm{G}$, de acuerdo al protocolo de Williams ${ }^{34}$. Los cariotipos fueron descritos de acuerdo a la nomenclatura del sistema internacional para citogenética humana ${ }^{35}$.

Recolección de muestras. Se recolectaron muestras de médula ósea con EDTA, separando los linfocitos con solución de Lymphoprep (Nycomed Pharma Norway). El concentrado de linfocitos se almacenó en isotiocianato de guanidina a $-70^{\circ} \mathrm{C}$ hasta su procesamiento. La extracción de ARN se realizó según el método de Chomczynski ${ }^{36}$.

RT-PCR. A partir del ARN mensajero se obtuvo un ADN complementario mediante la reacción de transcriptasa reversa (enzima M-MLV Gibco), el cual se usó en cada uno de los casos para amplificar secuencias específicas de los genes de fusión TEL/AML1 y los reordenamientos del gen de fusión BCR/ABL que generan las proteínas p190 y p 210 (Figuras 1 y 2). Como control interno

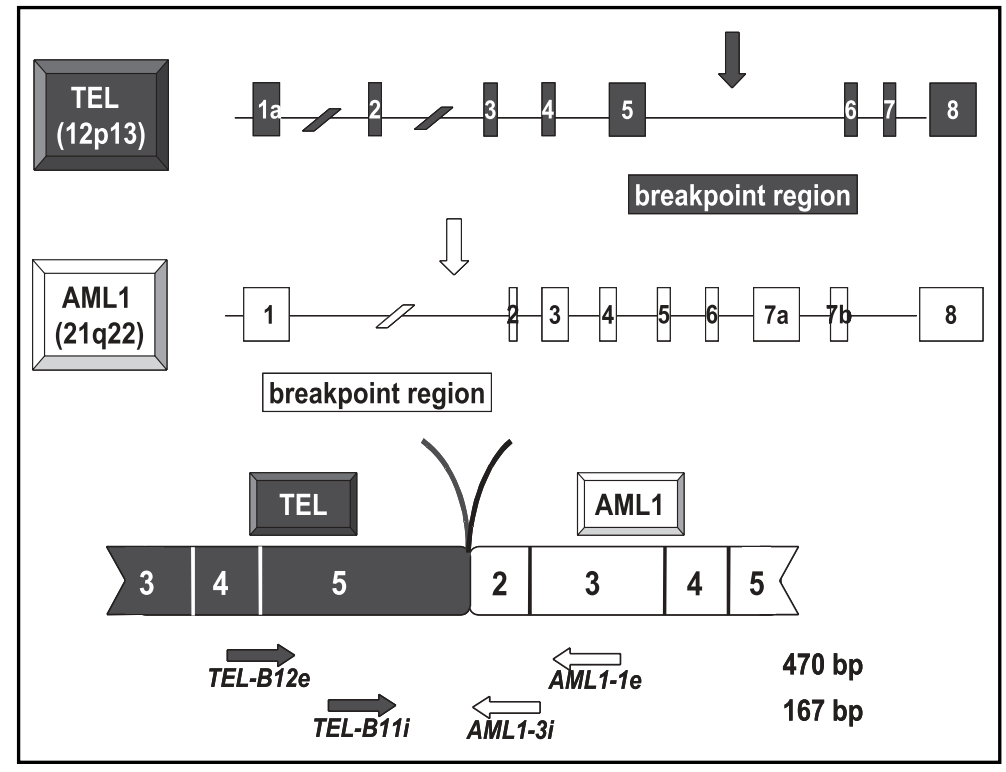

Figura 1. Representación esquemática del gen de fusión TEL/AML1. Las flechas verticales indican los puntos de quiebre más relevantes del gen TEL y del gen AML1. La figura inferior representa el gen de fusión TEL/AML1. Las flechas horizontales indican la posición de los partidores utilizados en este estudio. Con los partidores externos en la primera amplificación se obtiene un tamaño de banda de $470 \mathrm{pb}$ y en la segunda amplificación con partidores internos de $167 \mathrm{pb}$. pb: pares de bases. 


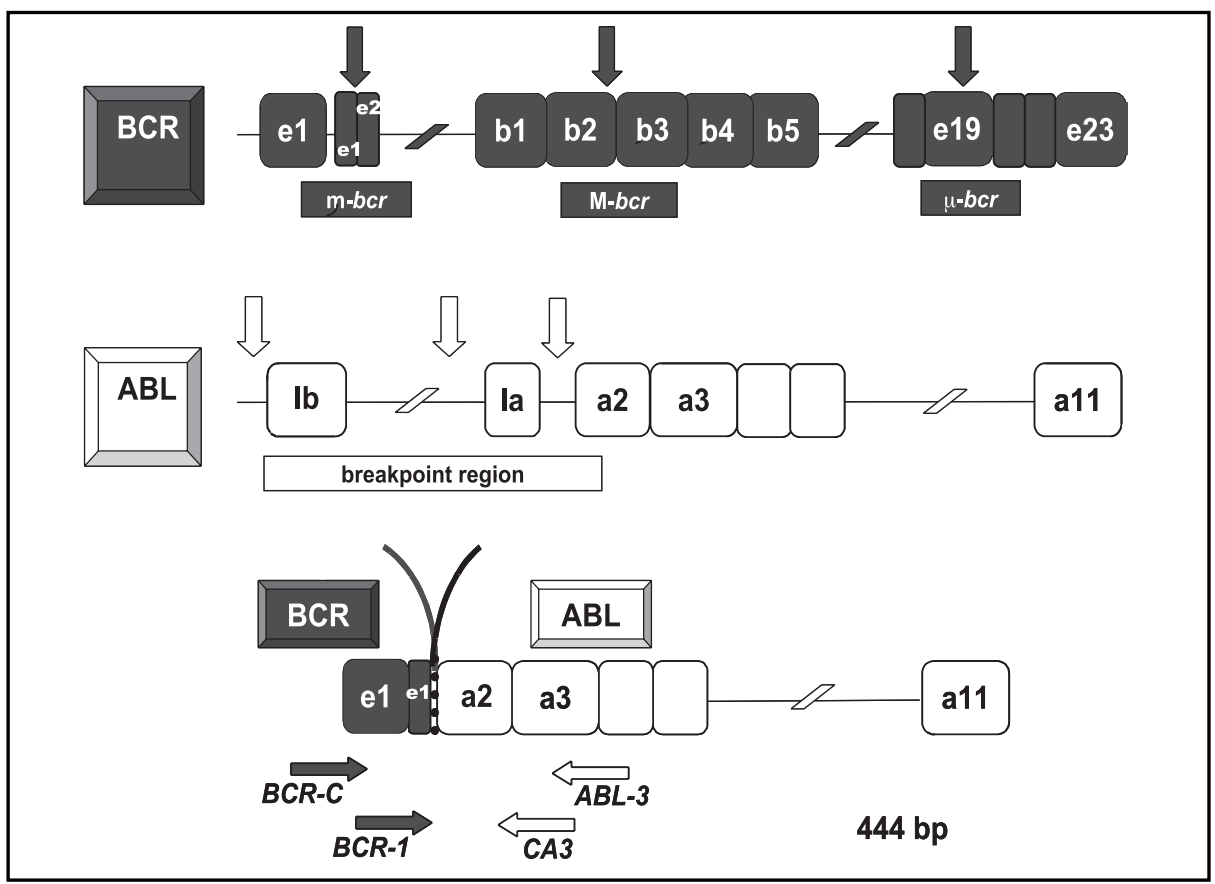

Figura 2. Representación esquemática del gen de fusión BCR/ABL. Las flechas verticales indican los puntos de quiebre más relevantes del gen BCR y del gen ABL. En el gen BCR se destacan las regiones m-bcr, M-bcr y $\mu$-bcr. La figura inferior representa el gen de fusión BCR/ABL con el reordenamiento e1a2 (444 pb), que da origen a la proteína de fusión p190. Las flechas horizontales indican la posición de los partidores utilizados en este estudio. pb: pares de bases.

se realizó una PCR simple, con partidores dirigidos al gen DRB1 ${ }^{37}$. Para amplificar los transcriptos de fusión TEL/AML1, se utilizó una PCR en nido con los siguientes partidores (IDT, USA): externo: B12e: 5' cgtggatttcaaacagtcca 3', AM1e: 5' cattgccagccatcacagtgac 3', interno: B11i: 5' aacctctctcatcgggaag 3', AM3i 5' acgcctcgctcatcttgcctg 3'14. Las condiciones de PCR fueron: para la primera amplificación 32 ciclos y $55-60-65^{\circ} \mathrm{C}$ de temperaturas de hibridación y para la segunda amplificación 35 ciclos y $55^{\circ} \mathrm{C}$. Para la amplificación de los transcriptos de fusión BCR/ABL se utilizaron los partidores $^{38}$ y las condiciones de la PCR en nido previamente publicados ${ }^{30,32}$.

El producto de la reacción se visualizó por electroforesis en gel de agarosa al $2 \%$ teñido con bromuro de etidio (Figuras 3 y 4). Todas las reacciones contaron con controles positivos y negativos.

Todos los pacientes fueron tratados en forma similar, siguiendo el protocolo nacional del PIN-
DA 96. Ninguno de los pacientes que fueron incluidos en este estudio recibió trasplante alogénico de médula ósea.

Estadística. La sobrevida libre de eventos (SLE) se calculó desde la fecha del diagnóstico hasta la fecha del primer evento (recaída o muerte), evaluación a septiembre de 2003. Para estimar la SLE se utilizó el método de Kaplan-Meier (software STATA 8.0).

\section{RESULTADOS}

La edad media del grupo total fue 5,3 años (rango 1 mes-14 años). Cinco niños eran menores de 12 meses. Respecto a la etnia de los pacientes de la IX región, 12/38 casos $(31,6 \%)$ correspondieron a la raza mapuche, cifra levemente mayor que la comunicada en el último censo en la región 


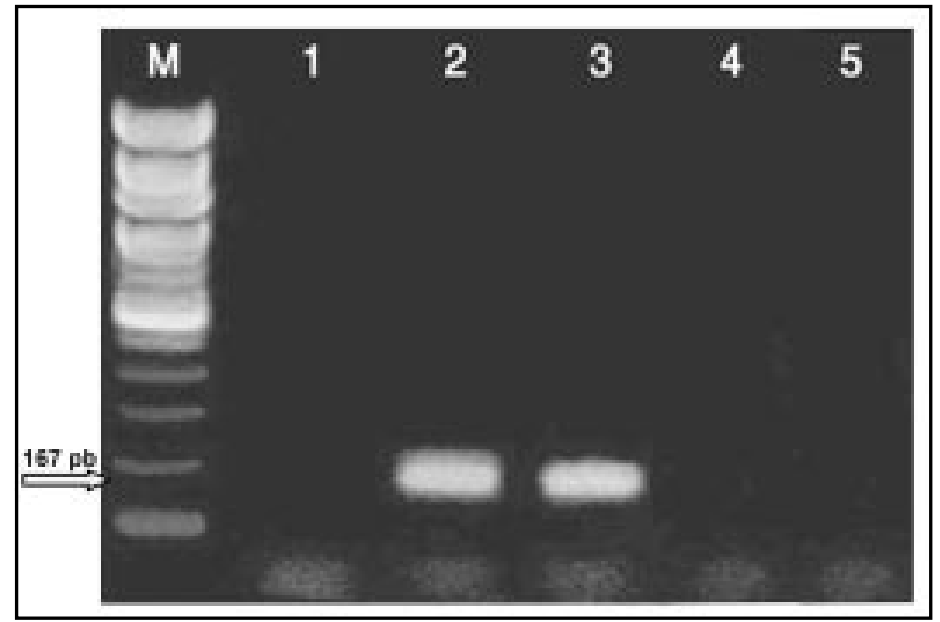

Figura 3. RT-PCR del transcripto del gen de fusión TEL/AML1. M: Marcador de ADN de $100 \mathrm{pb}$. Carril 1: Paciente negativo. Carril 2: Paciente № 2 TEL/ AML1 positivo. Carril 3: Control positivo. Carril 4: Control negativo. Carril 5: Control blanco. Las bandas representan un fragmento de $167 \mathrm{pb}$. Visualización en gel de agarosa al $2 \%$ teñido con bromuro de etidio.

pb: pares de bases.

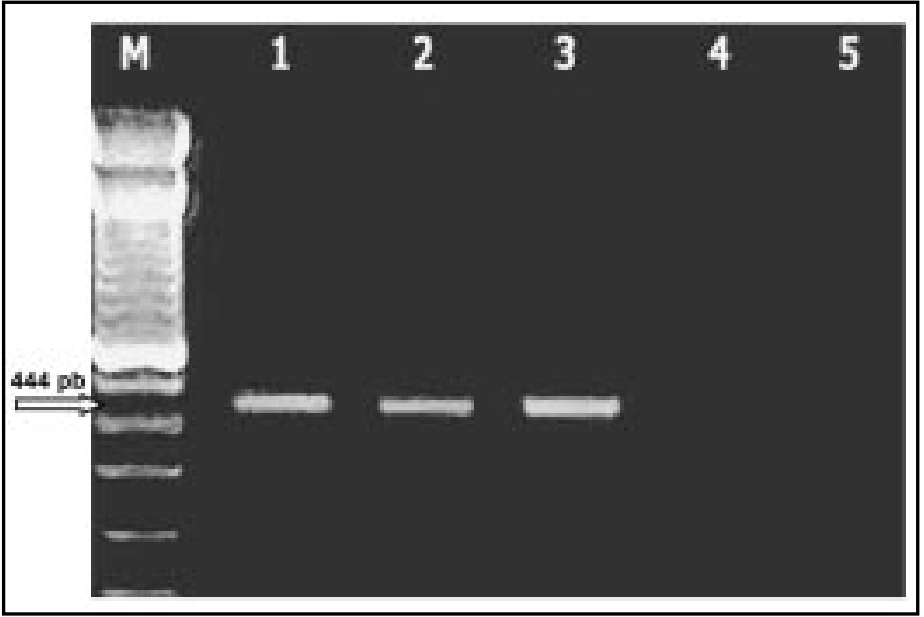

Figura 4. RT-PCR del transcripto del gen de fusión BCR/ABL. Reordenamiento e1a2 (p190). M: Marcador de ADN de 100 pb. Carril 1: Paciente № 14 BCR/ABL positivo. Carril 2: Paciente № 15 BCR/ABL positivo. Carril 3: Control positivo. Carril 4: Control negativo. Carril 5: Control blanco. Las bandas representan un fragmento de $444 \mathrm{pb}$. Visualización en gel de agarosa al $2 \%$ teñido con bromuro de etidio. pb: pares de bases.

$(23,3 \%)^{39}$. El recuento de leucocitos medio fue $34,7 \times 10^{9} / 1$ (rango 0,8-351 x109/1).

Las características generales promedio del total de los pacientes pediátricos según presentación del gen de fusión, se presentan en la Tabla 1.

Estudio de BCR/ABL Se detectó esta alteración en 2/56 niños (3,6\%), de 9 y 14 años. Estos pacientes presentaron una recaída medular muy precoz, falleciendo a los 3 y 5 meses del diagnóstico. Ambos presentaban recuento leucocitario mayor a $150 \times 10^{9} / 1$, morfología FAB-L2 e inmunofenotipo común. La sobrevida de los pacientes que presentaron el gen $\mathrm{BCR} / \mathrm{ABL}(+)$ fue significativamente peor $(p<0,001)$.
Estudio de TEL/AML1. Se detectó este transcripto en $13 / 56(23,2 \%)$ niños, con una media de edad de 6,3 años (rango 1,3-14 años), concentrándose la mayoría entre 2 y 6 años (8/13). El recuento leucocitario promedio fue de $8,7 \times 10^{9} / 1$ (rango 1,9-51,8 x109/1), la morfología FAB de los linfoblastos correspondió en 11 pacientes a L1 y en 2 niños a L2. La mayoría presentó fenotipo común. De los 13 casos TEL/AML1(+), 12 tuvieron buena respuesta a la prednisona. La sobrevida libre de eventos (SLE) a los 40 meses fue de $63 \%$ en el grupo TEL/AML1(+) y de 54\% en el grupo TEL/ AML1(-), sin diferencias estadísticamente significativas (Figura 5). Del grupo TEL/AML1(+), 8 pacientes se mantienen en remisión completa (37, 
Tabla 1. C aracterísticas generales de los pacientes con LLA estudiados, agrupados según presentación del gen de fusión

\begin{tabular}{|lcccccccc|}
\hline & $\begin{array}{c}\text { Edad } \\
\text { (años) }\end{array}$ & $\begin{array}{c}\text { Leucocitos } \\
\text { x } 10^{9} / 1\end{array}$ & $\begin{array}{c}\text { a } 40 \\
\text { meses }\end{array}$ & $\begin{array}{c}\text { SLE } \\
\text { rango } \\
\text { (meses) }\end{array}$ & $\begin{array}{c}\text { Mediana } \\
\text { (meses) }\end{array}$ & Fallecidos & Total & n \\
\hline $\begin{array}{l}\text { TEL/AML1 } \\
\text { positivo } \\
\text { TEL/AML1 } \\
\text { negativo }\end{array}$ & 6,3 & 8,7 & $63 \% *$ & $4-41$ & 16 & 5 & 13 & 23,2 \\
\hline & 42,8 & $54 \% *$ & $1-47$ & 14 & 21 & 43 & 76,8 \\
\hline $\begin{array}{l}\text { BCR/ABL } \\
\text { positivo } \\
\text { BCR/ABL } \\
\text { negativo }\end{array}$ & 11,5 & 210,0 & $0 \% * *$ & $3-5$ & 4 & 2 & 2 & 3,6 \\
\hline
\end{tabular}

*: $\mathrm{p}=0,75 . \quad$ **: $\mathrm{p}<0,01$.

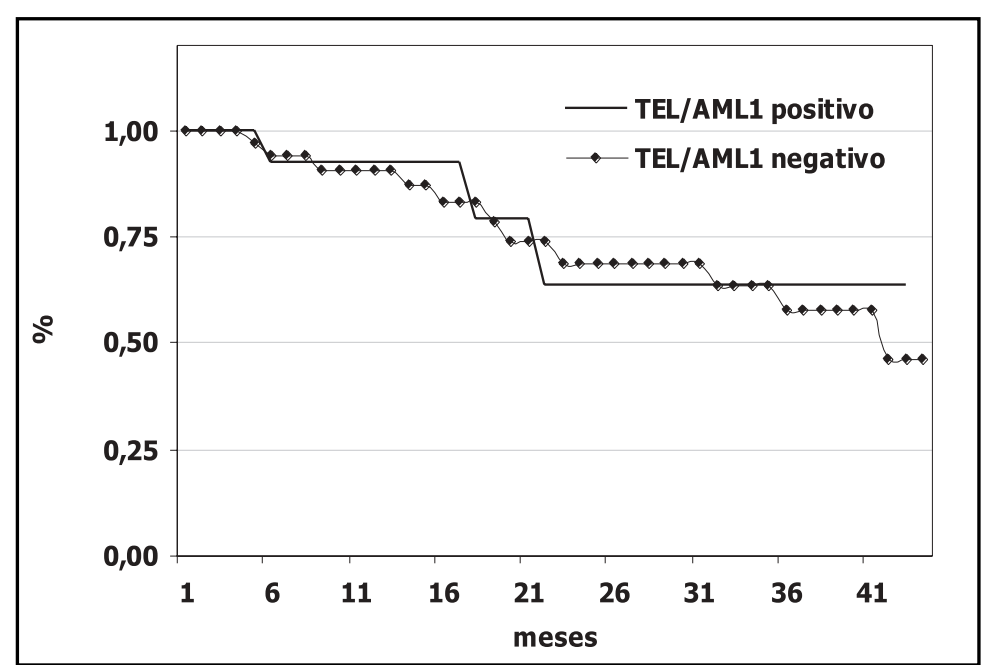

Figura 5. Estimación de Kaplan Meier para sobrevida libre de evento (SLE), de niños con LA. Las curvas representan los pacientes TEL/AML1 positivo $(n=13)$ y TEL/AML1 negativo $(n=43)$. Entre ambos grupos no se observó significación estadística ( $\mathrm{p}>0,05)$.

39, 40 y 41 meses), estando 4 de ellos fuera de tratamiento. Un paciente falleció en remisión completa a los 7 meses por un cuadro séptico. Cuatro pacientes presentaron recaída medular a los 4, 6, 14 y 20 meses; en uno de estos pacientes, la recidiva coincidió con la suspensión transitoria del tratamiento debido a infección fúngica severa.
Sin considerar este último caso, la recaída medular del grupo TEL/AML1(+) fue de $23 \%$. El paciente con recaída a los 14 meses, fue estudiado nuevamente, detectándose la misma alteración molecular (TEL/AML1) que al diagnóstico.

El inmunofenotipo en los niños TEL/AML1(+) fue de estirpe B común en 12/13 casos y preB en 
1/13. En el grupo TEL/AML1(-) fue común en 36/ 41 , preB en $3 / 41$ y proB en $2 / 41$ casos. Del total de niños estudiados, cuatro casos presentaron coexpresión de antígenos mieloide (un caso positivo y tres casos negativos para el gen de fusión TEL/AML1).

El estudio citogenético sólo se realizó en 9/18 casos de la región Metropolitana (2 positivos y 7 negativos para el gen TEL/AML1). Los 2 casos TEL/AML1(+) presentaron un número modal de 92, uno de ellos con $\operatorname{del}(12)(\mathrm{p} 12)$ y el otro add(13)(q34). Los 7 casos TEL/AML1(-) presentaron un número modal de 46 en 6 casos y 54 en 1 caso. Dos de ellos presentaron alteraciones estructurales de $\operatorname{add}(21)(q 22)$ y $\operatorname{del}(11)(q 23)$. Los pacientes de Temuco no contaron con estudio citogenético, por no estar esta técnica disponible en la IX región.

Las características clínicas y hallazgos de laboratorio de los casos con estudio molecular positivo se presentan en la Tabla 2.

\section{Discusión}

Los resultados del presente estudio de un grupo de niños chilenos no seleccionados, muestran una incidencia similar a la descrita en la literatura ${ }^{11-}$ 18,23 , respecto a la expresión de los transcriptos del gen de fusión TEL/AML1 y BCR/ABL en niños, usando RT-PCR.

Las características clínicas de los pacientes con LA, TEL/AML1(+) coinciden con la descripción de la literatura en el sentido de presentarse en niños con recuento leucocitario bajo, inmunofenotipo común y buena respuesta a la prednisona. La RT-PCR es de gran utilidad para detectar esta anomalía, que no es detectada por el estudio citogenético (anomalía críptica). En uno de los dos niños con estudio citogenético se observó del(12)(p12); estas deleciones del brazo corto del cromosoma 12 se han detectado por citogenética convencional en más de $10 \%$ de los casos de LA infantili ${ }^{37}$. La translocación del gen TEL puede ir

Tabla 2. Características clínicas de los pacientes con LLA TEL/AM L y BCR/ABL positivo

\begin{tabular}{|c|c|c|c|c|c|c|c|c|c|}
\hline № & $\begin{array}{l}\text { Edad } \\
\text { (años) }\end{array}$ & Sexo & $\begin{array}{c}\text { Leucocitos } \\
\text { x } 10^{9} / 1\end{array}$ & FAB & $\begin{array}{l}\text { Inmuno- } \\
\text { fenotipo }\end{array}$ & Estudio citogenético & $\begin{array}{l}\text { Gen de fusión } \\
\text { positivo }\end{array}$ & $\begin{array}{c}\text { Respuesta } \\
\text { a la prednisona }\end{array}$ & $\begin{array}{c}\text { SLE } \\
\text { (meses) }\end{array}$ \\
\hline 1 & 1,3 & F & 51,8 & L1 & Común & $\begin{array}{c}\text { 46,XX(5651)46,XX, } \\
\operatorname{del}(12)(\mathrm{p} 12) / \\
92, \mathrm{XXXX} / 46, \mathrm{XX}(5883)\end{array}$ & TEL/AML1 & MRP & $4^{*}$ \\
\hline 2 & 2,9 & M & 6,3 & L1 & Común & $\mathrm{NR}$ & TEL/AML1 & BRP & 39 \\
\hline 3 & 3 & M & 2,5 & L1 & Común & NR & TEL/AML1 & $\mathrm{BRP}$ & 37 \\
\hline 4 & 3,1 & M & 4,1 & L1 & Común & NR & TEL/AML1 & $\mathrm{BRP}$ & 40 \\
\hline 5 & 4 & $\mathrm{~F}$ & 2,0 & L1 & Común & NR & TEL/AML1 & BRP & 18 \\
\hline 6 & 4 & M & 2,5 & L1 & Pre-B & NR & TEL/AML1 & $\mathrm{BRP}$ & 5 \\
\hline 7 & 4,3 & M & 3,5 & L1 & Común & NR & TEL/AML1 & $\mathrm{BRP}$ & 41 \\
\hline 8 & 5 & M & 3,7 & $\mathrm{~L} 2$ & Común & NR & TEL/AML1 & $\mathrm{BRP}$ & $16^{*}$ \\
\hline 9 & 6,8 & M & 16,5 & L1 & Común & NR & TEL/AML1 & $\mathrm{BRP}$ & $20 *$ \\
\hline 10 & 9 & $\mathrm{~F}$ & 2,2 & L1 & Común & $\begin{array}{c}46, \mathrm{XX} \\
\operatorname{add}(13)(\mathrm{q} 34)[4 \mathrm{y} \\
\text { 92,XXXX[17y 46,XX[9] }\end{array}$ & TEL/AML1 & BRP & $7^{*}$ \\
\hline 11 & 12 & M & 12,3 & L1 & Común & NR & TEL/AML1 & $\mathrm{BRP}$ & 5 \\
\hline 12 & 13 & M & 3,8 & L1 & Común & NR & TEL/AML1 & BRP & 5 \\
\hline 13 & 14,9 & M & 2,4 & $\mathrm{~L} 2$ & Común & NR & TEL/AML1 & BRP & 8* \\
\hline 14 & 9 & M & 180,0 & L2 & Común & NR & BCR/ABL & $\mathrm{BRP}$ & $5^{*}$ \\
\hline 15 & 14,8 & M & 241,0 & L2 & Común & NR & BCR/ABL & $\mathrm{BRP}$ & $3^{*}$ \\
\hline
\end{tabular}

NR: No realizado. BRP: Buena Respuesta a la Prednisona. MRP: Mala Respuesta a la Prednisona. *Fallecido. 
acompañada por otras aberraciones genéticas secundarias, como deleción del otro alelo TEL, duplicación del gen de fusión o trisomía 21, observadas en $36 \%$ de los niños con LIA TEL/ AML1(+), los que tendrían un rol sinérgico con la proteína de fusión en la represión de la transcripción, influyendo en la progresión de la enferme$\operatorname{dad}^{38-43}$.

El porcentaje de recaída medular de $23 \%$ observado en el grupo TEL/AML1(+), está en concordancia al publicado por De Haas (23\%) en una serie de 17 pacientes TEL/AML1 $(+)^{44}$. La SLE estimada a 40 meses, aunque es levemente mayor en el grupo TEL/AML1(+) que en el grupo TEL/ AML1(-) (63\% y 54\%, respectivamente), no es estadísticamente significativa, hallazgo concordante con algunos estudios que no muestran diferencia significativa en la SLE de pacientes TEL/AML1 positivo y negativo ${ }^{45}$.

En general, podemos comentar que aunque nuestro grupo de estudio fue pequeño y el tiempo de seguimiento corto, la SLE estimada a 40 meses del total de los niños con LLA es similar a los

\section{REFERENCIAS}

1. SAWYERS C. Molecular genetics of acute leukaemia. Lancet 1997; 349: 196-200.

2. Pui CH, Evans W. Acute lymphoblastic leukemia. N Engl J Med 1998; 339: 605-15.

3. Pui CH, Rewnng M, Downing J. Mechanisms of Disease: Acute Lymphoblastic Leukemia. N Eng J Med 2004; 350: 1535-48.

4. Look AT. Genes altered by chromosomal translocations in leukemias and lymphomas. En: Vogelstein B, Kenneth $\mathrm{K}$. The genetics basic of human cancer. New York: McGraw-Hill, 1998; 109-41.

5. Biondi A, Cimino, G, Pieters R, Pui CH. Biological and therapeutic aspects of infant leukaemia. Blood 2000; 96: 24-33.

6. Van Dongen JJ, Macintyre EA, Gabert JA, Delabesse E, Rossi V, SAGLO G ET AL. Standardized RT-PCR analysis of fusion gene transcripts from chromosome aberrations in acute leukemia for detection of minimal residual disease. Report of the BIOMED-1 Concerted Action: investigation of minimal residual disease in acute leukemia. Leukemia 1999; 13: 1901-28.

7. Golub TR, Barker GF, Bohlander SK, Hiebert SW, Ward DC, Bray-Ward P et al. Fusion of TEL gene resultados publicados del protocolo nacional chileno LLA PINDA 87 (SLE a 5 años de 60\%) ${ }^{46}$.

Por otra parte, la frecuencia del gen de fusión BCR/ABL en niños con LA en nuestro estudio, estuvo dentro de los rangos descritos en la literatura. A pesar de la baja incidencia, su presencia otorga al paciente un peor pronóstico, lo que hace imprescindible realizar su determinación en forma rutinaria. Aun cuando sólo 2 casos presentaron el gen de fusión $\mathrm{BCR} / \mathrm{ABL}$, estos pacientes fallecieron precozmente, mostrando una diferencia estadísticamente significativa ( $p<0,01$ ).

En resumen, las técnicas de biología molecular que permiten la detección de transcriptos de genes de fusión presentes en la LAA mediante RTPCR, montadas en nuestro laboratorio, constituyen un importante aporte para la mejor caracterización de las alteraciones genéticas en las enfermedades onco-hematológicas de nuestra población. Las cuales serán de gran utilidad en el diagnóstico y monitoreo de estas enfermedades siendo el punto de partida para el desarrollo de la hematooncología moderna en nuestra región.

on 12p13to the AML1 gene on 21q22 in acute lymphoblastic leukemia. Proc Natl Acad Sci USA 1995; 92: 4917-21.

8. Wiemels J, Ford A, van Wering E, Postma A, Greaves M. Protracted and variable latency of acute lymphoblastic leukemia after TEL/AML1 gene fusion in utero. Blood 1999; 94: 1057-62.

9. Ford AM, Fasching K, Panzer-Grumayer R, Koening M, HAAS O, GREAVES MF. Origins of date» relapse in childhood acute lymphoblastic leukaemia with TEL-AML1 fusion genes. Blood 2001; 98: 558-64.

10. GReaves M, Wiemels J. Origins of chromosome translocations in childhood leukaemia. Nature Rev Cancer 2003; 3: 1-11.

11. Magalhaes IQ, Pombo-De-Olveira MS, Bennett CA, Cordova JC, DobBIN J, Ford AM et al. TEL-AML1 fusion gene frequency in paediatric acute lymphoblastic leukaemia in Brazil. Br J Haematol 2000; 111: $204-7$.

12. Uckun FM, Pawisgaard N, Hokland P, NavarRa C, NarLa R, Gaynon PS ET aL. Expression of TEL-AML1 fusion transcripts and response to induction therapy in standard risk acute lymphoblastic leukaemia. Leuk Lymphoma 2001; 42: 41-56.

13. Borkhardt A, CazZaniga G, Viehmann S, Valsecchi MG, Ludwig W-D, BuRci L et al. Incidence and 
clinical relevance of TEL/AML1 fusion genes in children with acute lymphoblastic leukemia enrolled in the German and Italian multicenter therapy trials. Blood 1997; 90: 571-7.

14. Romana SP, Poirel M, Leconiat M, Fiexor MA, MauchaufFe M, Jonveaux P ET al. High frequency of $\mathrm{t}(12 ; 21)$ in childhood B-lineage acute lymphoblastic leukemia. Blood 1995; 86: 4263-9.

15. Trka J, Zuna J, Hrusak O, Kalinova M, Muzikova K, Lauschman H ET al. Impact of TEL-AML1-positive patients on age distribution of childhood acute lymphoblastic leukemia in Czech Republic. Leukemia 1998; 12: 996-1007.

16. Ozbek U, Sirma S, Agaoglu L, Yuksel L, Anak S, YILDIZ I ET AL. Prognostic significance of the TELAML1 fusion gene in pediatric acute lymphoblastic leukemia in Turkey. J Pediatr Hematol Oncol 2003; 25: 204-8.

17. Amor DJ, Algar em, Slater HR, Smith PJ. High frequency of $t(12 ; 21)$ in childhood acute leukemia detected by RT-PCR. Pathology 1998; 30: 3815.

18. Endo C, Oda M, Nishiuchi R, Seino Y. Persistence of TEL-AML1 transcript in acute lymphoblastic leukemia in long-term remission. Pediatrics Int 2003; 45: 275-80.

19. Hubeek I, Ramakers-van Woerden NL, Pieters R, Slaterr, Beverloo HB, van Wering E et al. TELAML1 fusion is not a prognostic factor in dutch childhood acute lymphoblastic leukemia. $\mathrm{Br} \mathrm{J}$ Haematol 2001; 113: 254-5.

20. Loh M, Silverman L, Young M, Neuberg D, Golub T, SALLAN S ET aL. incidence of TEL/AML1 fusion in children with relapsed childhood acute lymphoblastic leukemia. Blood 1998; 92: 4792-7.

21. Rubnitz JE, Shuster JJ, Land VJ, Link MP, PuLen J, CamitTa BM et aL. Case control study suggests a favorable impact of TEL rearrangement in patients with B lineage acute lymphoblastic leukemia treated with antimetabolite based therapy: A Pediatric Oncology Group study. Blood 1997; 89: 1143-6.

22. Attarbaschi A, Mann G, König M, Dworzak MN, TREBO MM, MüHLEgGer N et al. Incidence and relevance of secondary chromosome abnormalities in childhood TEL/AML1+ acute lymphoblastic leukaemia: an interphase FISH analysis. Leukemia 2004; 18: 1611-16.

23. Hann I, Vora A, Harrison G, Harrison C, Eden O, HIL F ET AL. Determinants of outcome after intensified therapy of childhood lymphoblastic leukaemia: results from Medical Research Council United Kingdom acute lymphoblastic leukaemia XI protocol. Br J Haematol 2001; 113: 103-14.

24. Seeger K, Stackelberg A, Taube T, Buchwald D, Korner G, SUtTorp M et al. Relapse of TEL-AML1positive acute lymphoblastic leukemia in childhood: A matched-pair analysis. J Clin Oncol 2001; 19: 3188-93.

25. Robinson HM, Broadfield ZJ, Cheung KL, Harewood L, HaRris RL, Jalali GR et al. Amplification of AML1 in acute lymphoblastic leukaemia is associated with a poor outcome. Leukemia 2003; 17: 2249-50.

26. Nowell PC, Hungerford DA. A minute chromosome in human chronic granulocytic leukemia. Science 1960; 132: 1497-500.

27. Beyermann B, Adams HP, Henze G. Philadelphia chromosome in relapsed childhood acute lymphoblastic leukemia; a matched-pair analysis. J Clin Oncol 1997; 15: 2231-7.

28. Uckun EM, Nachmann JB, Sather HN, Sensel MG, Kraft P, Stenherz PG et al. Poor treatment outcome of Philadelphia chromosome positive pediatric acute lymphoblastic leukemia despite intensive chemotherapy. Leuk Lymph 1999; 33: 101-6.

29. Barriga F, Risueño C, Legues ME, Campbel M, TORDESILA J ET AL. Transcriptos de fusión TELAML1 en niños con Leucemia linfoblástica Aguda (LA) de estirpe B. Rev Chil Cancerología y Hematología 1997; 7: 226 (Abstract).

30. Artigas CG, Melo A, Roa JC, Páez E, Vittini C, ARRiagada M ET al. Detección de secuencias del gen BCR-ABL mediante RT-PCR en pacientes con leucemia en la IX Región. Chile. Rev Méd Chile 2002; 130: 623-30.

31. Cabrera ME, Campreil M, Quintana J, Undurraga $S$, Ford A, Graves M. Significado clínico y frecuencia de la alteración genético/molecular 11q23/MLL en lactantes con leucemia aguda en Chile. Rev Méd Chile 2001; 129: 634-42.

32. Artigas CG, Melo A, Roa JC, Roa I, Quijada I, VItTINI C ET AL. Transcriptos de fusión del gen BCR/ABL en pacientes con leucemia mieloide crónica. Int J Morphol 2003; 21: 205-9.

33. Cabrera ME, Labra $S$, Ugarte $S$, Matutes E, Greaves MF. Inmunofenotipo, características clínicas y laboratorio de la leucemia linfoblástica aguda en Chile. Rev Méd Chile 1996; 124: 293-9. 
34. Wiшams DL, Harris A, Wiшams KJ, Brosius MJ, LEMONDS W. A direct bone marrow chromosome technique for acute lymphoblastic leukaemia. Cancer Genet Cytogenet 1984; 13: 239-57.

35. Mitelman F. Standing Committee on Human Cytogenetic. ISCN 1995. An International System for Human Cytogenetic Nomenclature. Recommendations of the International Standing Committee on Human Cytogenetic Nomenclature. Memphis, Tennessee: Basel S Karger Pub, 1995.

36. Chomczynski P, SAcchi N. Single-step method of RNA isolation by acid guanidinium thiocyanatephenol-chloroform extraction. Anal Biochem 1987; 162: 156-9.

37. Artigas CG, Melo A. Gen DRB-1: Su utilidad como control interno en la técnica de reacción en cadena de la polimerasa con transcriptasa reversa (RT-PCR). Rev Chil Cs Méd Biol 2000; 10: 47-50.

38. CRoss N. Detection of BCR-ABL in Hematological Malignancies by RT-PCR. En: Cotter F. ed. Molecular diagnosis of cancer. Totowa, New Jersey: Humana Press, 1996; 25-36.

39. CENSO 2002. Comisión Nacional del XVII Censo de Población y VI de Vivienda. Santiago de Chile, Marzo, 2003. Consultado en: http://www.ine.cl/ cd2002/etnia.pdf

40. Borowitz M, Digiuseppe J. Acute Lymphoblastic Leukemia. En: Knowles D. ed. Neoplastic Hematopathology. Philadelphia: Lippincott Williams \& Wilkins, 2001; 1643-65.

41. Raynaud S, Cave H, Baens M, Bastard C, Cacheux V, Grosgeorge J et al. The 12;21 Translocation
Involving TEL and Deletion of the Other TEL Allele: Two Frequently Associated Alterations Found in Childhood Acute Lymphoblastic Leukemia. Blood 1996; 87: 2891-9.

42. Ma SK, Wan TS, Cheuk AT, Fung LF, Chan GC, CHANg SY ET AL. Characterization of additional genetic events in childhood acute lymphoblastic leukemia with TEL/AML1 gene fusion: a molecular cytogenetics study. Leukemia 2001; 15: 14427.

43. Douet-Guilbert N, Morel F, Le Bris MJ, Herry A, Le Calvez G, Marion V et al. A fluorescence in situ hybridization study of TEL/AML1 fusion gene in B-cell acute lymphoblastic leukemia (1984-2001). Cancer Genet Cytogenet 2003; 144: 143-7.

44. de Haas V, Oosten L, Dee R, Verhagen O, Kroes W, VAN DER BERg H ET AL. Minimal residual disease studies are beneficial in the follow - up of TEL / AML1 patients with B-precursor acute lymphoblastic leukaemia. Br J Haematol 2000; 111: 10806.

45. Tsang KS, L CK, Chik KW, Shing MM, Tsoi WC, Ng MH ET AL. TEL/AML1 rearrangement and the prognosis significance in childhood acute lymphoblastic leukemia in Hong Kong. Am J Hematol 2001; 68: 91-8.

46. Campbell M, Salgado C, Quintana J, Becker A, VARGaS L, CABRERA ME ET AL. Mejoría en el pronóstico de la leucemia linfoblástica aguda en niños de un país en desarrollo: Resultados del protocolo nacional chileno PINDA 87. Rev Chil Pediatr 1999; 70: 405-14.

Agradecimientos

A Concepción Risueño A., Biólogo del Departamento de Hematología-Oncología, Facultad de Medicina, Pontificia Universidad Católica de Chile, por su asesoría en el control y validación de las técnicas de biología molecular empleadas en este estudio. Al Sr. Sergio Muñoz N. PhD Bioestadística, Director del CIGES, Universidad de la Fronte$\mathrm{ra}$, por su asesoría estadística. A TM Neda Marinov, Laboratorio Hematología Hospital del Salvador, Santiago, por la realización del estudio de inmunofenotipo. A la Dra. Myriam Campbell B., Coordinadora Nacional Protocolo Leucemias Infantil (PINDA), por sus comentarios al trabajo. 